\title{
CdSe Nanorods Functionalized with Thiol-anchored
}

\section{Oligothiophenes}

Bryan C. Sih and Michael O. Wolf*

Department of Chemistry, University of British Columbia, Vancouver, BC, Canada,

V6T 1Z1

\section{Supporting Information}

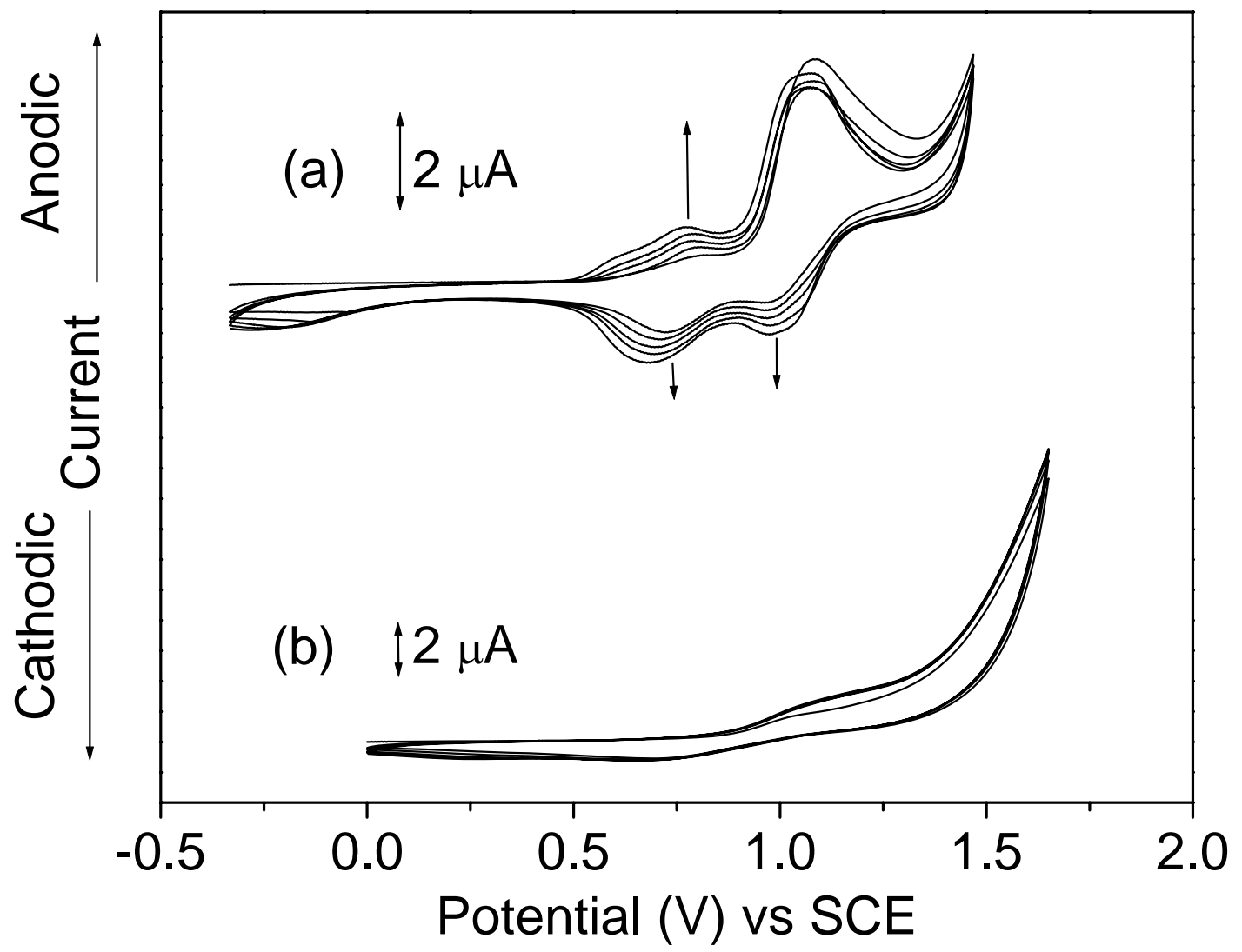

Figure S1. Cyclic voltammetry of (a) 3 and (b) 3-CdSe (5 cycles) from 0 to $1.3 \mathrm{~V}$ in $\mathrm{CH}_{2} \mathrm{Cl}_{2}$ containing $0.1 \mathrm{M}\left(\mathrm{C}_{4} \mathrm{H}_{9}\right) \mathrm{NPF}_{6}$. The arrows indicate the direction of current change with each successive scan. 


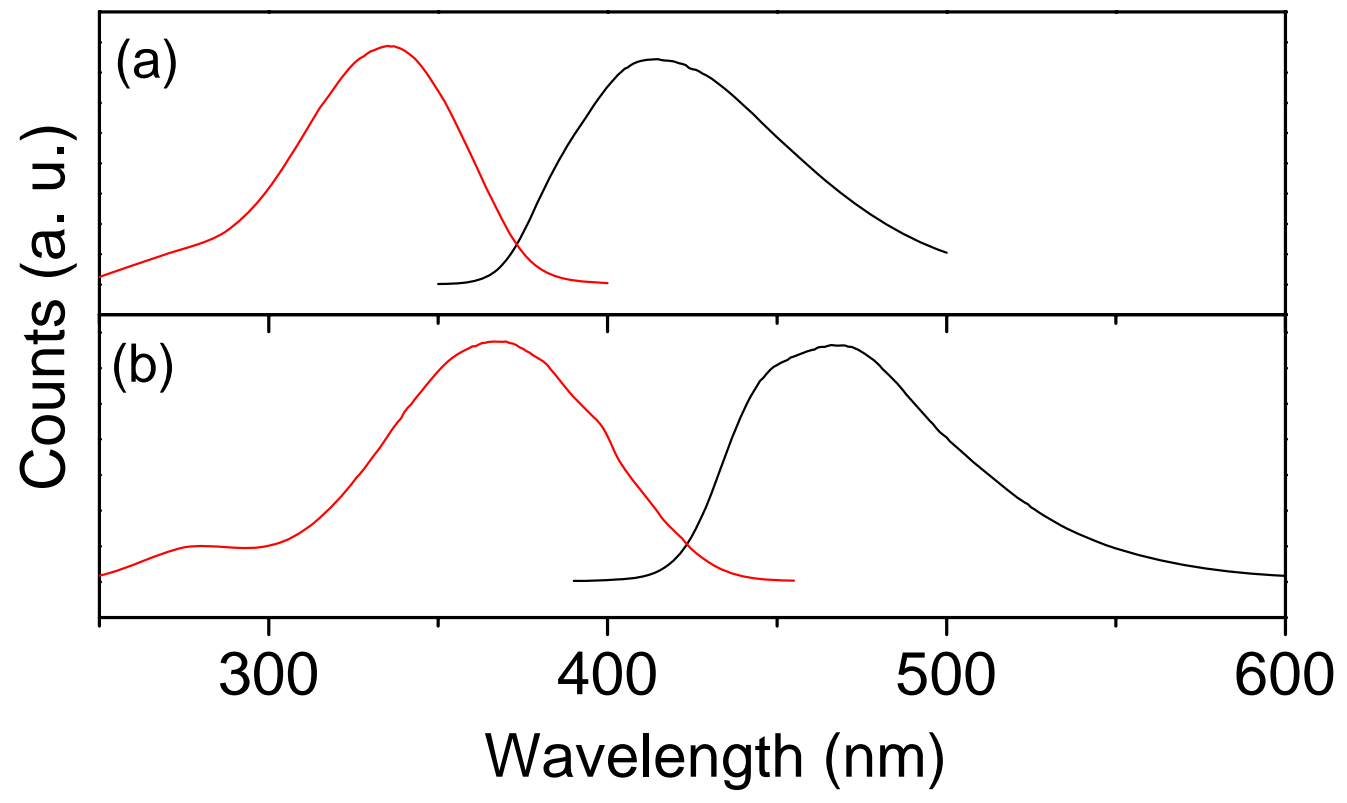

Figure S2. Excitation (-) and emission (-) spectra of the capping groups (a) 2 and (b) 3 in $\mathrm{CHCl}_{3}$ excited at 326 and $363 \mathrm{~nm}$, respectively.

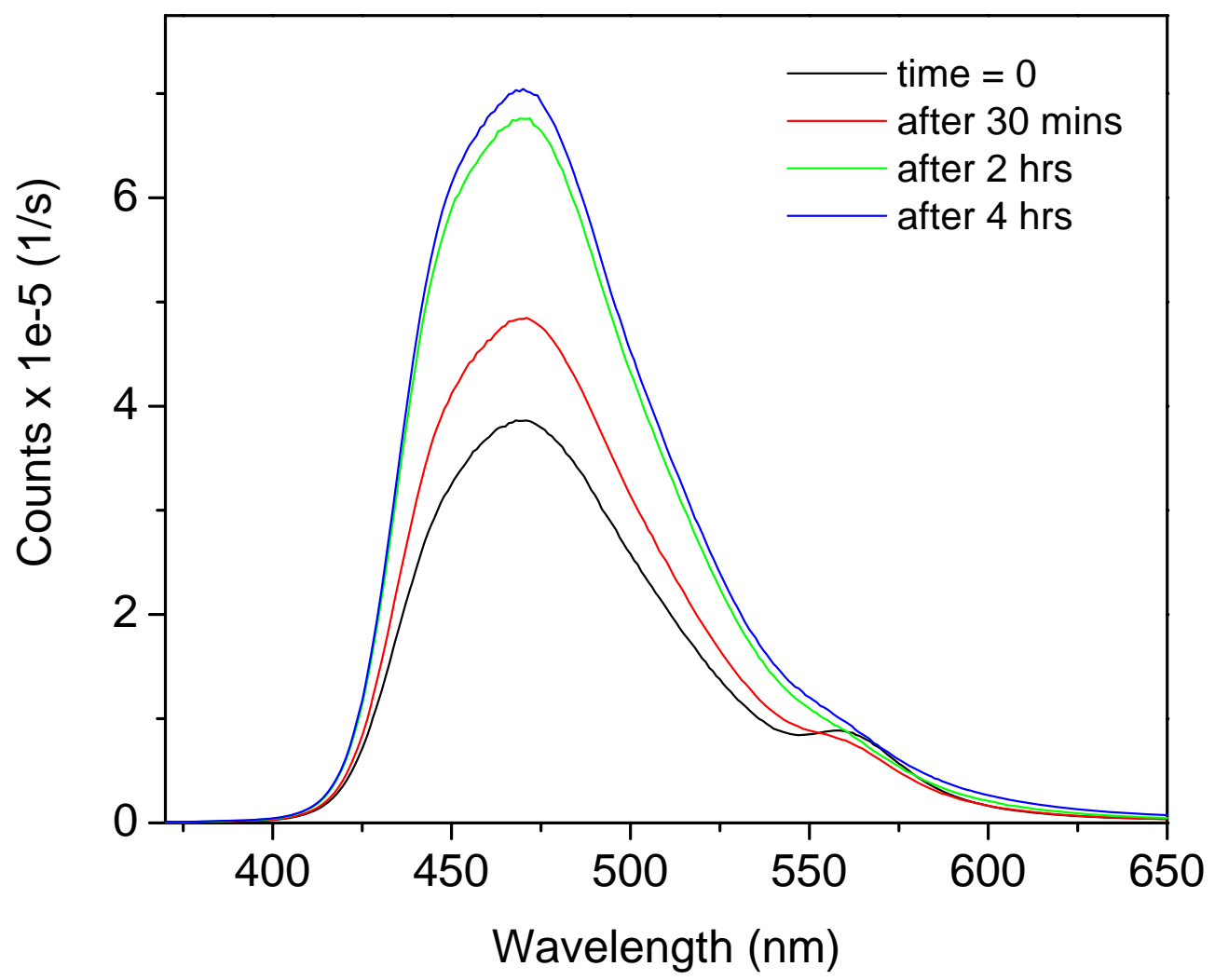

Figure S3. Emission spectra of 3-CdSe as a function of time. 


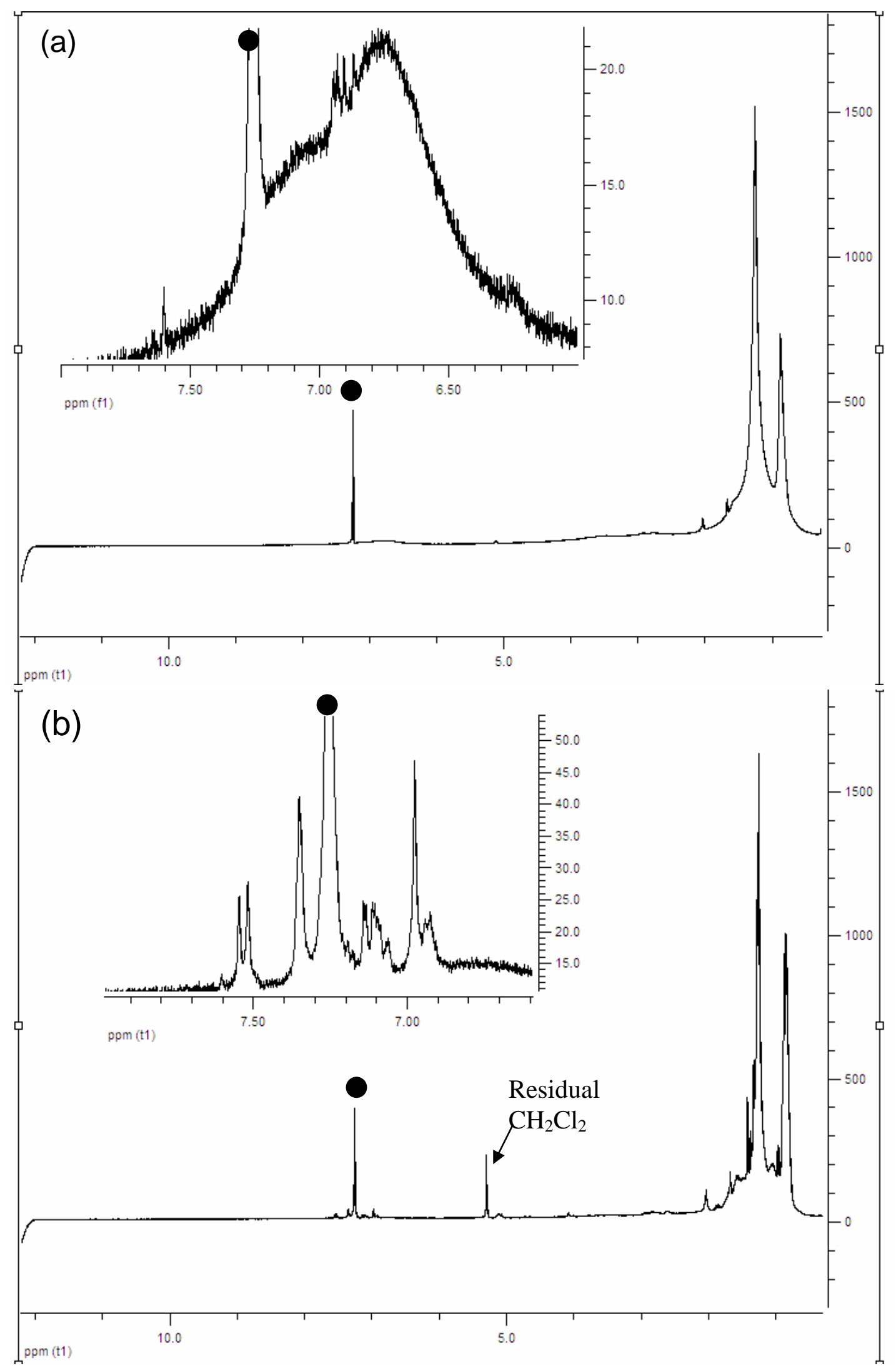




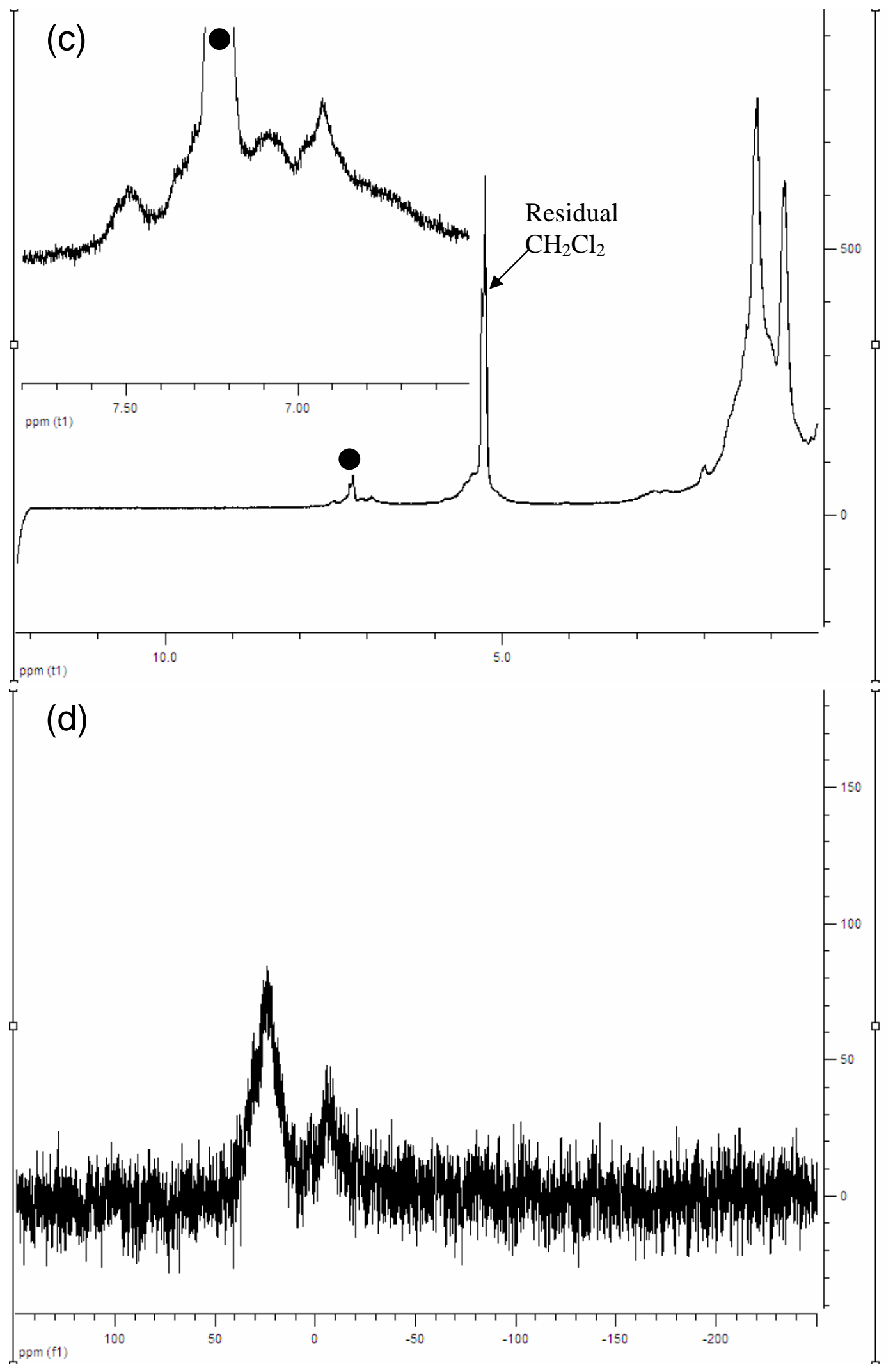



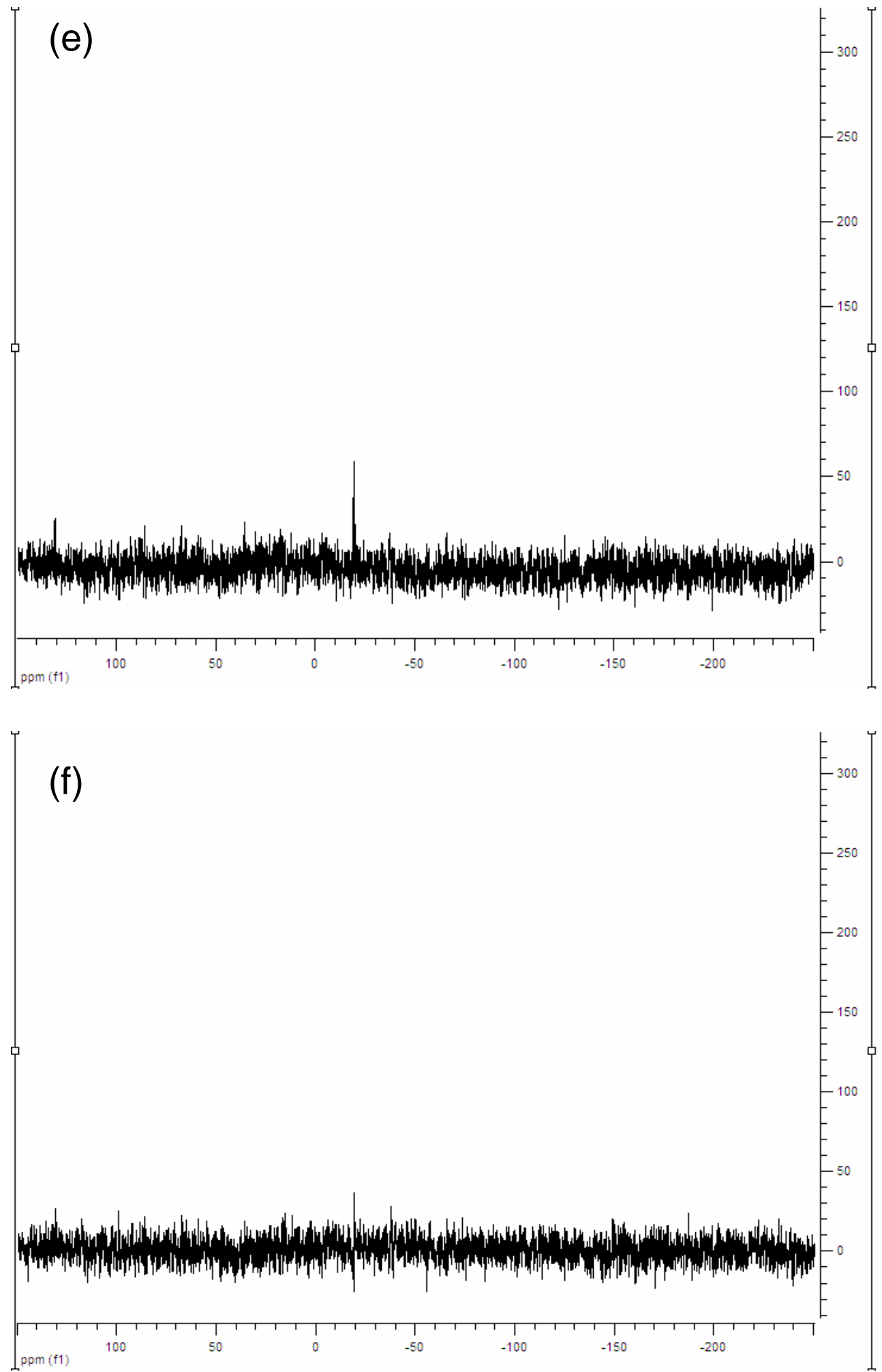

Figure S4. ${ }^{1} \mathrm{H}$ NMR spectra of (a) 1-CdSe, (b) 2-CdSe and (c) 3-CdSe dissolved in $\mathrm{CDCl}_{3}(300 \mathrm{MHz}$ ). Insets: expansion of the oligothiophene region. The $(\bullet)$ indicates the proton signal of residual $\mathrm{CHCl}_{3}$ present in the solvent. ${ }^{31} \mathrm{P}$ NMR spectra of (d) 1-CdSe, (e) 2-CdSe and (f) 3-CdSe dissolved in $\mathrm{CDCl}_{3}(300 \mathrm{MHz}$ ). 

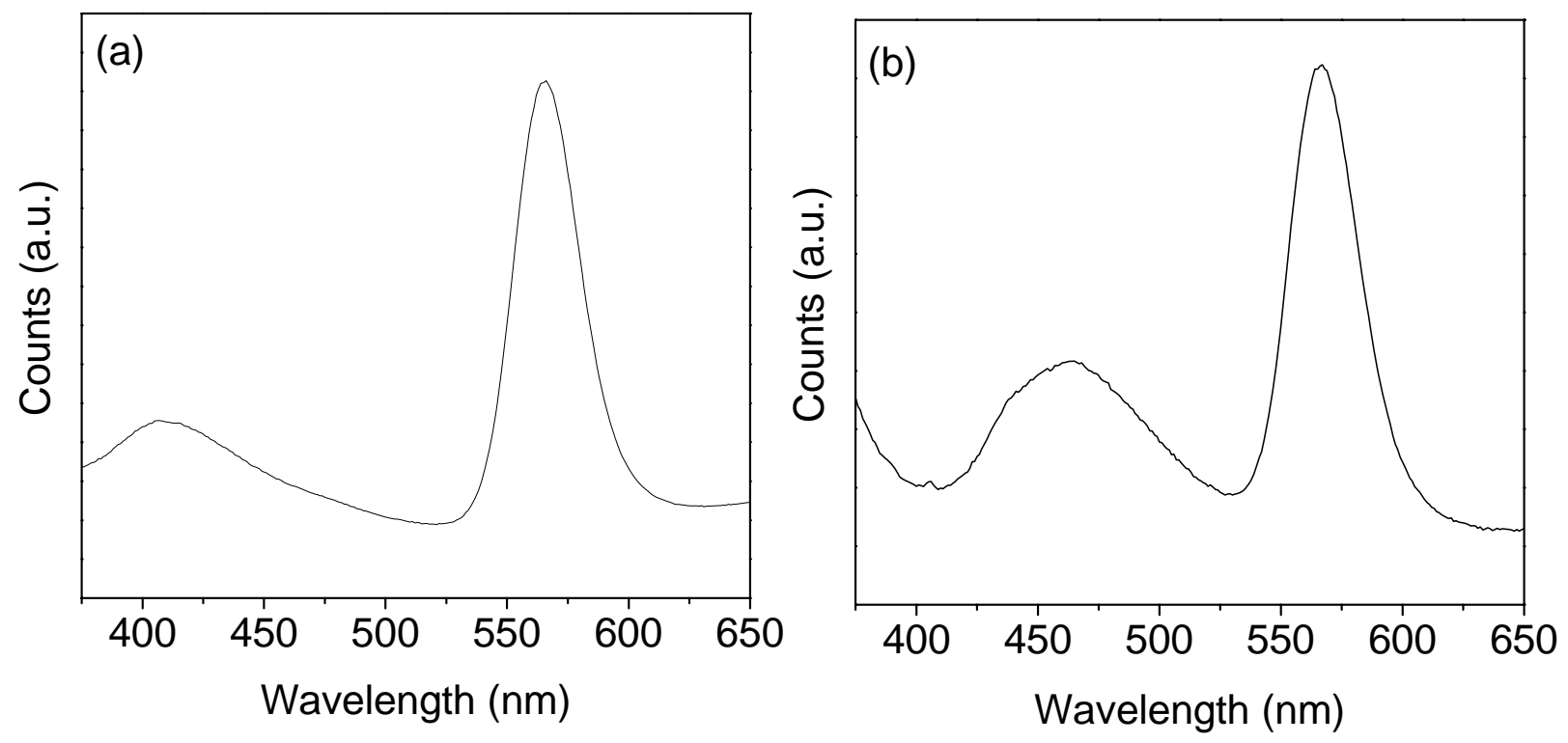

Figure S5. Solid-state emission spectra of (a) 2-CdSe and (b) 3-CdSe. 